\title{
Lovastatin exerts protective effects on endothelial cells via upregulation of PTK2B
}

\author{
WEIWEI CHU ${ }^{1}$, LILI GUAN ${ }^{2}$, DIHUA HUANG ${ }^{2}$, YUEZHONG REN ${ }^{3}$ and YAN ZHOU ${ }^{4}$ \\ Departments of ${ }^{1}$ Cadre Health Care and ${ }^{2}$ Endocrinology and Metabolism, Shaoxing People's Hospital, \\ Shaoxing Hospital of Zhejiang University, Shaoxing, Zhejiang 312000; ${ }^{3}$ Department of Endocrinology and Metabolism, \\ The Second Affiliated Hospital of Zhejiang University School of Medicine, Hangzhou, Zhejiang 310009; \\ ${ }^{4}$ Department of Cardiovascular Medicine, Shaoxing People's Hospital, Shaoxing \\ Hospital of Zhejiang University, Shaoxing, Zhejiang 312000, P.R. China
}

Received March 24, 2015; Accepted June 6, 2016

DOI: $10.3892 /$ etm.2016.3547

\begin{abstract}
Statins are HMG-CoA reductase inhibitors that are used to decrease the blood levels of low-density lipoprotein (LDL). In addition, they have been shown to exert pleiotropic protective effects in the absence of LDL-lowering activity. The present study investigated the effects of lovastatin on global gene expression in human umbilical vein endothelial cells (HUVECs), in order to further explore its ability to protect against oxidized (ox)-LDL-induced cytotoxicity. HUVECs were treated with lovastatin for 2-24 h, and gene expression patterns were analyzed using cDNA microarrays. The results suggested that numerous genes were regulated by lovastatin, including certain genes associated with cell survival, such as $P T K 2 B, B C L 2$ and $M A P 3 K 3$. In particular, $P T K 2 B$, which has been shown to exert anti-apoptotic effects against ox-LDL-induced cell injury, was upregulated by lovastatin. Knockdown of $P T K 2 B$ was able to attenuate ox-LDL-induced cell injury, and this was associated with decreased levels of phosphorylated-AKT and eNOS, and inhibition of mitochondrial-dependent apoptosis. In conclusion, the results of the present study suggested that lovastatin protects against ox-LDL-induced cell injury, potentially via the upregulation of $P T K 2 B$, which regulates the anti-apoptosis signaling pathway.
\end{abstract}

\section{Introduction}

Statins are widely used for the treatment of hypercholesterolemia and to decrease the risk of cardiovascular disease (1). Statins act by inhibiting the conversion of $\mathrm{HMG}-\mathrm{CoA}$ to

Correspondence to: Dr Lili Guan, Department of Endocrinology and Metabolism, Shaoxing People's Hospital, Shaoxing Hospital of Zhejiang University, 641 Middle People's Road, Shaoxing, Zhejiang 312000, P.R. China

E-mail: 2209650201@qq.com

Key words: lovastatin, PTK2B, human umbilical vein endothelial cells, p-AKT, apoptosis mevalonate, which is a rate-limiting step in the cholesterol biosynthesis pathway and thus lowering the LDL-cholesterol in the blood (2). Previous clinical trials have demonstrated that statins are able to substantially decrease cardiovascular-associated morbidity and mortality in patients with and without coronary disease (3-5). Since serum cholesterol levels have been closely associated with coronary artery disease (6), it was initially hypothesized that the ability of statins to lower cholesterol levels was the predominant mechanism underlying the observed reduction in the risk of cardiovascular diseases (7). However, it has since emerged that the therapeutic benefits of statins may not solely be explained by their cholesterol-lowering effects $(8,9)$; it was reported that patients treated with statins were less susceptible to cardiovascular incidents, independent of cholesterol lowering (10). Therefore, mechanisms other than cholesterol-lowering may underlie the ability of statins to protect against cardiovascular incidents.

Statins have been shown to directly improve endothelial function and promote vascular relaxation by increasing the synthesis of nitric oxide by endothelial nitric oxide synthase (eNOS) (11), and by reducing the levels of angiopoietin-2 (12), which are important regulatory factors in endothelial cells for protection against the development of arteriosclerosis $(13,14)$. In addition, statins promote atherosclerotic plaque stability (15) and decrease the production of reactive oxygen species from monocytes and macrophages (16). Furthermore, statins reduce pro-inflammatory cytokine expression and oxygen radical formation (17-19), while they are also associated with a reduced risk of Alzheimer's disease (1). Impairment of vascular endothelial cells, which may result from increased production of reactive oxygen species and decreased synthesis or secretion of endothelial-derived nitric oxide (20-22), has been shown to be involved in the pathogenesis of arteriosclerosis and other cardiovascular diseases (23). Therefore, maintenance of vascular endothelial function is important to prevent cardiovascular disease $(24,25)$. However, to the best of our knowledge, no previous study has systematically investigated the effects of statins on endothelial cells, and thus it is difficult to mechanistically illustrate their beneficial clinical effects. 
Therefore, the present study used cDNA microarrays to investigate the effect of lovastatin on global gene expression patterns in human umbilical vein endothelial cells (HUVECs), in order to identify unknown intracellular targets of statins and potential mediators of the pleiotropic effects observed for this drug. The results of the present study may provide further insights into the mechanisms underlying the pleiotropic effects of statins and their anti-atherogenic potential.

\section{Materials and methods}

Reagents. Lovastatin (Sigma-Aldrich, St. Louis, MO, USA) was converted to an active form as described previously (26). Briefly, inactive lovastatin was dissolved in warm $\left(55^{\circ} \mathrm{C}\right)$ ethanol, followed by the addition of $0.6 \mathrm{M} \mathrm{NaOH}$ and $\mathrm{H}_{2} \mathrm{O}$, and was incubated at room temperature for $30 \mathrm{~min}$. Subsequently, $\mathrm{HCl}$ was used to adjust the final solution to $\mathrm{pH} 8.0$, and the lovastatin solution was stored as a $10 \mathrm{mM}$ stock at $-20^{\circ} \mathrm{C}$. Rabbit polyclonal anti-SGK3 (1:1,000, ab153981), rabbit monoclonal anti-ATP2B1 (1:1000, ab190355), rabbit monoclonal anti-PTK2B (1:1,000, ab32571), rabbit polyclonal anti-eNOS (1:1,000, ab5589), rabbit monoclonal anti-MAP3K3 (1:2,000, ab40756) and rabbit polyclonal MAP4K3 (1:2,000, ab103481) antibodies were purchased from Abcam (Cambridge, MA, USA). In addition, rabbit polyclonal anti-BCL2 (1:1,000, 2872), rabbit monoclonal anti-BAX (1:1,000, 5023), mouse monoclonal anti-caspase-3 (1:500, 9668), mouse monoclonal anti-AKT(1:2,000, 2920), rabbit monoclonal anti-p-AKT $(1: 1,000,4060)$ and mouse monoclonal $\beta$-actin $(1: 5,000$, 3700) antibodies were purchased from Cell Signaling Technology, Inc. (Danvers, MA, USA).

Cell culture. HUVECs were purchased from ATCC (Manassas, VA, USA) and maintained in Dulbecco's modified Eagle's medium (Invitrogen; Thermo Fisher Scientific, Inc., Waltham, MA, USA) supplemented with $10 \%$ fetal bovine serum (Gibco; Thermo Fisher Scientific, Inc.). Cells were cultured at $37^{\circ} \mathrm{C}$ in a $5 \% \mathrm{CO}_{2}$ atmosphere until further use, and were seeded in 6 -well plates at a density of $4 \times 10^{5}$ cells per well. For dose-response experiments, the cells were treated with various concentrations of lovastatin for $24 \mathrm{~h}(0.1,0.5,2.5$ and $12.5 \mu \mathrm{M})$. For time-course experiments, the cells were treated with $0.5 \mu \mathrm{M}$ lovastatin for various durations $(2,6$, 12 and $24 \mathrm{~h}$ ). Control cells were treated with $0.1 \%$ dimethyl sulfoxide (vehicle).

Cellular cholesterol measurement. Total cholesterol was extracted from the cells according to a previously described method (27), with minor modifications. Briefly, cells were harvested and washed twice with phosphate-buffered saline (PBS). Next, extraction was performed with $1 \mathrm{ml}$ isopropanol, followed by sonication for $20 \mathrm{~min}$ at $4^{\circ} \mathrm{C}$, and centrifugation at $10,000 \mathrm{x}$ g for $10 \mathrm{~min}$ at $4^{\circ} \mathrm{C}$. The supernatant was evaporated under a vacuum and the pellet was resuspended in $20 \mu \mathrm{l}$ isopropanol for the determination of cellular cholesterol. Cholesterol levels were measured using a Total Cholesterol Detection kit (1021; Jiemen Biotechnology Corp., Shanghai, China). Subsequently, the sediment fractions were lysed using a Mammalian Cell Extraction kit (K269-500; BioVision, Inc., Milpitas, CA, USA), and total protein levels were quantified using the Bradford method (P0006; Beyotime Institute of Biotechnology).

cDNA microarray. Total RNA was extracted from the cells using TRIzol reagent (Invitrogen; Thermo Fisher Scientific, Inc.), followed by purification on an RNeasy column (74104; Qiagen, Inc., Valencia, CA, USA) and quantification by UV absorption using a 2000 Nanodrop spectrophotometer (Thermo Fisher Scientific, Inc., Wilmington, DE, USA). RNA quality was assessed using an Agilent 2100 Bioanalyzer (Agilent Technologies, Inc., Santa Clara, CA, USA). A cDNA microarray analysis was conducted according to a previous study (28). Briefly, a home-made microarray was used and reverse transcription was done using an Ambion RETROscript reverse transcription kit (AM1710). Samples from three wells of the vehicle-treated group were pooled and used as a reference to label Cy3 (GE Healthcare Life Sciences). RNA from the drug treated cells was isolated in triplicate and labeled with Cy5 individually. Cy3- and Cy5-labeled cDNA pools were mixed to hybridize. Hybridization was performed at $56^{\circ} \mathrm{C}$ for $16 \mathrm{~h}$ and washes were performed and followed by scanning on an Axon 4000B Scanner (Axon Instruments, Sunnyvale, CA, USA). In total 8,583 genes/expressed sequence tags were selected according to signal intensity. Gene expression profiling for each time point was conducted with Significance Analysis of Microarrays software, version 2.20 (http://statweb.stanford. edu/ tibs/SAM/), with One Class response type (false discovery rate $<0.01)$. Genes were considered as differentially expressed when their fold-change was $>1.5$-fold. The function of these differentially-expressed genes was searched with bioinformatics tools including KEGG (http://www.genome.jp/kegg/) and DAVID (https://david.ncifcrf.gov/) pathway analysis.

Reverse transcription-quantitative polymerase chain reaction $(R T-q P C R)$. A total of $2 \mu \mathrm{g}$ of total RNA was used for reverse transcription using an Ambion RETROscript reverse transcription kit (AM1710). Next, the cDNA was diluted 1:20 for RT-qPCR. RT-qPCR was conducted on an ABI 7300 Real-Time PCR system (Applied Biosystems; Thermo Fisher Scientific, Inc.) with SYBR Green I fluorescent dye (Toyobo Co., Ltd., Osaka, Japan). The PCR reaction contained $1 \mu \mathrm{l}$ of cDNA, $1 \mu \mathrm{l}$ of primers $(5 \mu \mathrm{M}), 8 \mu \mathrm{l}$ of $\mathrm{H}_{2} \mathrm{O}$ and $10 \mu \mathrm{l}$ of reaction mixture with a total volume of $20 \mu \mathrm{l}$. The reactions were performed in triplicate at $94^{\circ} \mathrm{C}$ for $15 \mathrm{~s}$ and $60^{\circ} \mathrm{C}$ for $1 \mathrm{~min}$ and 40 cycles. GAPDH was used as an internal control. Gene expression was evaluated with the $2^{-\Delta \Delta C t}$ method (27). The primer sequences of the genes used for qPCR were designed with primer express 2.0 and are listed in Table I.

Cell counting kit (CCK)- 8 assay. Following the treatment of HUVECs with various concentrations of lovastatin for $24 \mathrm{~h}$ or $0.5 \mu \mathrm{M}$ lovastatin for various durations, cell viability was determined by adding $10 \mu \mathrm{l} \mathrm{CCK}-8$ solution (Dojindo Molecular Technologies, Inc., Kumamoto, Japan), followed by incubation at $37^{\circ} \mathrm{C}$ for $2 \mathrm{~h}$. Absorbance at $450 \mathrm{~nm}$ was measured using a SpectraMax 190 Microplate Reader (Molecular Devices, LLC, Sunnyvale, CA, USA). In each assay, four parallel wells were run and experiments were conducted in triplicate. In addition, cells were treated with oxidized (ox)-low-density lipoprotein (LDL), lovastatin or 
Table I. Gene names and polymerase chain reaction primer sequences.

\begin{tabular}{|c|c|c|}
\hline Gene name & Forward primer $\left(5^{\prime}-3^{\prime}\right)$ & Reverse primer $\left(5^{\prime}-3^{\prime}\right)$ \\
\hline$B C L 2$ & AАAATTTCCTGCATCTCATG & TATTGGATGTGCTTTGCATT \\
\hline$P T K 2 B$ & GCCCAGCCGACCTAAGTACAG & CGTAGGAGAGCTGGCACACA \\
\hline$M A P 3 K 3$ & GAGAGCGTGACCCGAAAGTA & GGATGTTGGCTCCCTTAATG \\
\hline$M A P 4 K 2$ & CAACTCCCAAGGTGCATATG & CGAGTAACAGGGTGAATCCA \\
\hline$C D C 7$ & AAGACGGAAAGGAGGGATCT & GCAGGGCTCTCATGTGAAAT \\
\hline SNPH & GCCAGCAACACCTATGAGAA & GGTACTGCACGAAGTCTGTCT \\
\hline$R A B 25$ & GCTGCAGAAGTCCCCTTACC & GGCGACAAATCTGTGTGTTG \\
\hline OVGP1 & TTGATGGTCTTGACCTTTTC & GCAAACAGGAGCTCTTCAAT \\
\hline$A T P 2 B 1$ & CATGTGTTAGGGCCCAGATT & TCTTTGCTTGGTCAGCACTCT \\
\hline$S G K 3$ & TGAAATGCTGTATGGATTGC & АСТСАСТССТGGCСТCAAAC \\
\hline
\end{tabular}

both for $24 \mathrm{~h}$, and then measured with CCK- 8 as described above, to assess the protective effect of lovastatin on injury induced by ox-LDL.

Cell apoptosis assay. To investigate the apoptosis of HUVECs, the cells were seeded at a density of $2 \times 10^{5}$ cells/well in a 6 -well plate and incubated at $37^{\circ} \mathrm{C}$ overnight. Subsequently, the cells were treated with ox-LDL, lovastatin or both for $24 \mathrm{~h}$, detached with $0.25 \%$ trypsin digestion and washed with cooled PBS. Next, cells were collected and resuspended in binding buffer containing Annexin-V and propidium iodide (Beyotime Institute of Biotechnology) and incubated for $15 \mathrm{~min}$ in the dark at room temperature. Apoptosis analyses were performed on a FACSCalibur flow cytometer (BD Biosciences, San Jose, CA, USA).

Western blot analysis. HUVECs were washed twice with ice-cold PBS and lysed in radioimmunoprecipitation assay buffer $(50 \mathrm{mM}$ Tris, $150 \mathrm{mM} \mathrm{NaCl}, 1 \%$ Triton $\mathrm{X}-100$, $0.1 \%$ SDS and $1 \%$ sodium deoxycholate; Beyotime Institute of Biotechnology, Haimen, China) containing protease and phosphatase inhibitors. Next, equal volumes of protein $(10 \mu \mathrm{g})$ were separated by $12 \%$ SDS-PAGE and transferred to Hybond-C nitrocellulose membranes (GE Healthcare Life Sciences, Little Chalfont, UK) in transfer buffer (192 mM glycine, $25 \mathrm{mM}$ Tris, $2.5 \mathrm{mM}$ SDS, $10 \%$ methanol). The blots were blocked with $5 \%$ nonfat milk in Tris-buffered saline supplemented with Tween-20 for $1 \mathrm{~h}$ at room temperature, followed by incubation with primary antibodies overnight at $4^{\circ} \mathrm{C}$. Subsequently, the membranes were incubated with horseradish peroxidase-conjugated secondary antibody (anti-rabbit IgG, 1:2,000; 7074; anti-mouse IgG, 1:2,000, 7076; Cell Signaling Technology, Inc.). The blots were developed with ECL Plus Western Blotting Detection Reagent (GE Healthcare Life Sciences) and analyzed using ImageJ software (1.43b; National Institutes of Health, Bethesda, MD, USA).

RNA silencing. Accell small interfering (si)RNA targeting $P T K 2 B$ was purchased from GE Dharmacon (GE Healthcare Life Sciences), with a scrambled siRNA used as the control (GE Healthcare Life Sciences). Transfection of HUVECs with
$P T K 2 B$ siRNA or scrambled siRNA was performed using Lipofectamine RNAiMAX (Thermo Fisher Scientific, Inc.), according to the manufacturer's instructions.

Statistical analysis. Data are presented as the mean \pm standard deviation. Comparisons between groups were conducted by one-way analysis of variance and least significant difference using SPSS software, version 19.0 (IBM SPSS, Armonk, NY, USA). $\mathrm{P}<0.05$ were considered to indicate a statistically significant difference.

\section{Results}

Effects of lovastatin on the cholesterol content of HUVECs. The effect of lovastatin on intracellular cholesterol content was evaluated. Lovastatin $(0.5,2.5$ and $12.5 \mu \mathrm{M})$ significantly decreased the cholesterol content of HUVECs following $24 \mathrm{~h}$ of incubation $(\mathrm{P}<0.05$; Fig. 1A). Notably, the cholesterol content was not significantly different between the 0.5, 2.5 and $12.5 \mu \mathrm{M}$ lovastatin-treated cells ( $\mathrm{P}>0.05$; Fig. $1 \mathrm{~A})$; therefore, $0.5 \mu \mathrm{M}$ lovastatin was used for the time-course experiment. As shown in Fig. 1B, lovastatin significantly decreased the cholesterol content of HUVECs following 12 and $24 \mathrm{~h}$ of treatment $(\mathrm{P}<0.05)$, but not after 2 or $6 \mathrm{~h}$ of treatment $(\mathrm{P}>0.05)$. Therefore, the duration of treatment with $0.5 \mu \mathrm{M}$ lovastatin was set at 2 and $24 \mathrm{~h}$, in order to observe short- and long-term gene expression profiles, which may be dependent or independent of cholesterol lowering.

Effects of lovastatin on the gene expression profile of $H U V E C s$. cDNA microarrays were used to analyze the effects of $0.5 \mu \mathrm{M}$ lovastatin on the gene expression profile of HUVECs after 2 and $24 \mathrm{~h}$ of treatment. The results indicated that the expression levels of a number of genes were altered by lovastatin. After $2 \mathrm{~h}$ of treatment with $0.5 \mu \mathrm{M}$ lovastatin, 12 genes were downregulated and 178 genes were upregulated, with fold-changes of $>1.5$ (data not shown). Similarly, after $24 \mathrm{~h}$ of treatment with $0.5 \mu \mathrm{M}$ lovastatin, 33 genes were downregulated and 77 genes were upregulated, presenting fold-changes of $>1.5$ (data not shown). These genes may represent unknown intracellular targets of lovastatin and require further clarification. 


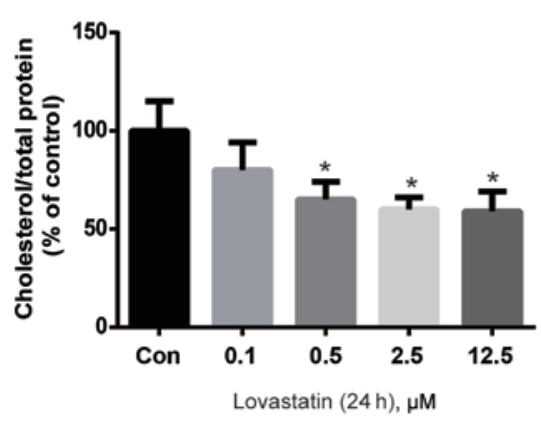

C

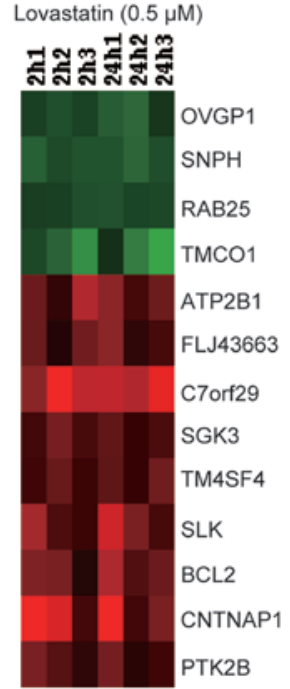

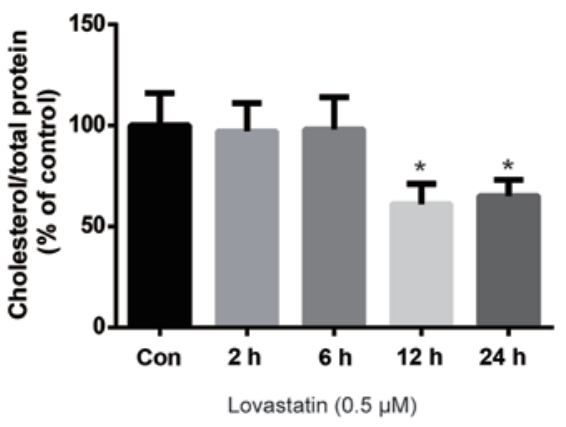

D

\begin{tabular}{|c|c|c|}
\hline Symbol & Fold change (2h) & Fold change (24 $\mathbf{h})$ \\
\hline OVGP1 & -0.756 & -0.884 \\
\hline SNPH & -0.902 & -0.931 \\
\hline RAB25 & -0.733 & -0.791 \\
\hline TMC01 & -1.092 & -1.191 \\
\hline ATP2B1 & 1.273 & 1.229 \\
\hline FLJ43663 & 0.993 & 0.991 \\
\hline C7orr29 & 2.183 & 2.212 \\
\hline SGK3 & 1.003 & 0.881 \\
\hline TM4SF4 & 0.891 & 1.009 \\
\hline SLK & 1.145 & 1.513 \\
\hline BCL2 & 1.092 & 1.376 \\
\hline CNTNAP1 & 2.085 & 1.759 \\
\hline PTK2B & 0.985 & 0.865 \\
\hline
\end{tabular}

Figure 1. Effect of lovastatin on the cholesterol content and gene expression profile of HUVECs. (A) Lovastatin (0.1, 0.5, 2.5 and 12.5 $\mu \mathrm{M})$ decreased the cholesterol content of HUVECs after $24 \mathrm{~h}$ of treatment. (B) $0.5 \mu \mathrm{M}$ lovastatin decreased the cholesterol content of HUVECs following 12 and $24 \mathrm{~h}$ of treatment. (C) Genes that were differentially expressed at 2 and $24 \mathrm{~h}$ of lovastatin treatment (fold-change $>1.5$; false discovery rate $<0.01$; green indicates downregulation and red indicates upregulation). (D) Fold-change of regulated genes after 2 and $24 \mathrm{~h}$ of lovastatin treatment. Data are expressed as the mean \pm standard deviation of three independent experiments. ${ }^{*} \mathrm{P}<0.05$ vs. the control cells. HUVECs, human umbilical vein endothelial cells.

Subsequently, the genes that were differentially expressed at 2 and $24 \mathrm{~h}$ of treatment were compared to identify which genes were altered at both treatment durations, since these may serve important roles in the effects of lovastatin on endothelial cells. As shown in Fig. 1C, 4 genes were downregulated at both 2 and 24 h of treatment, including $O V G P 1, S N P H, R A B 25$ and TMCO1, whereas the ATP2B1, FLJ43663, C7orf29, SGK3, TM4SF4, SLK, BCL2, CNTNAP1 and PTK2B genes were upregulated at 2 and $24 \mathrm{~h}$ of treatment (the fold change is summarized in Fig. 1D). According to the known functions of these genes, such as SGK3, ATP2B1 and PTK2B involved in cell proliferation and survival, (29-31), it may be hypothesized that they are independent of the cholesterol-lowering effects of lovastatin and likely respond to lovastatin as early as $2 \mathrm{~h}$ after treatment. Therefore, further investigation into the biological significance of these genes may be important.

Critical genes regulated by lovastatin in HUVECs. The results of the cDNA microarray analysis were verified by qPCR. As is shown in Fig. 2A, the qPCR results for the majority of genes were consistent with the microarray results, including the upregulation of $B C L 2, P T K 2 B, M A P 3 K 3, M A P 4 K 2, A T P 2 B 1$ and $S G K 3$, and the downregulation of $S N P H, R A B 25$ and $O V G P 1$. Whether alterations in the expression levels of these genes resulted in alterations in protein expression was unclear.
Therefore, the protein expression levels of certain important genes (according to their known function) were analyzed by western blot analysis. The results demonstrated that SGK3, ATP2B1, PTK2B, BCL2 and MAP3K3 were all upregulated by lovastatin, which was consistent with the alteration of their gene expression levels, with the exception of MAP4K2 (Fig. 2B). Since SGK2, ATP2B1, PTK2B and MAP3K3 are associated with cell proliferation and survival (29-32), and BCL2 is an anti-apoptosis protein (33), it may be hypothesized that lovastatin may affect cell proliferation. However, the viability of HUVECs was not significantly altered by lovastatin following $24 \mathrm{~h}$ of treatment ( $\mathrm{P}>0.05$; Fig. 2C).

Lovastatin protects HUVECs against ox-LDL-induced cytotoxicity via the PTK2B/AKT signaling pathway. Since lovastatin did not affect the viability of HUVECs after $24 \mathrm{~h}$ of treatment, the ability of lovastatin to protect HUVECs against ox-LDL-induced cytotoxicity was investigated. As is shown in Fig. 3A, $20 \mu \mathrm{g} / \mathrm{ml}$ ox-LDL significantly reduced the viability of HUVECs after $24 \mathrm{~h}$ of treatment $(\mathrm{P}<0.05)$. Although lovastatin did not significantly affect the viability of HUVECs after $24 \mathrm{~h}$ of treatment, it was able to significantly protect HUVECs against ox-LDL-induced injury $(\mathrm{P}<0.05)$. In addition, the ability of lovastatin to protect HUVECs against ox-LDL-induced apoptosis was evaluated (Fig. 3B and C). 

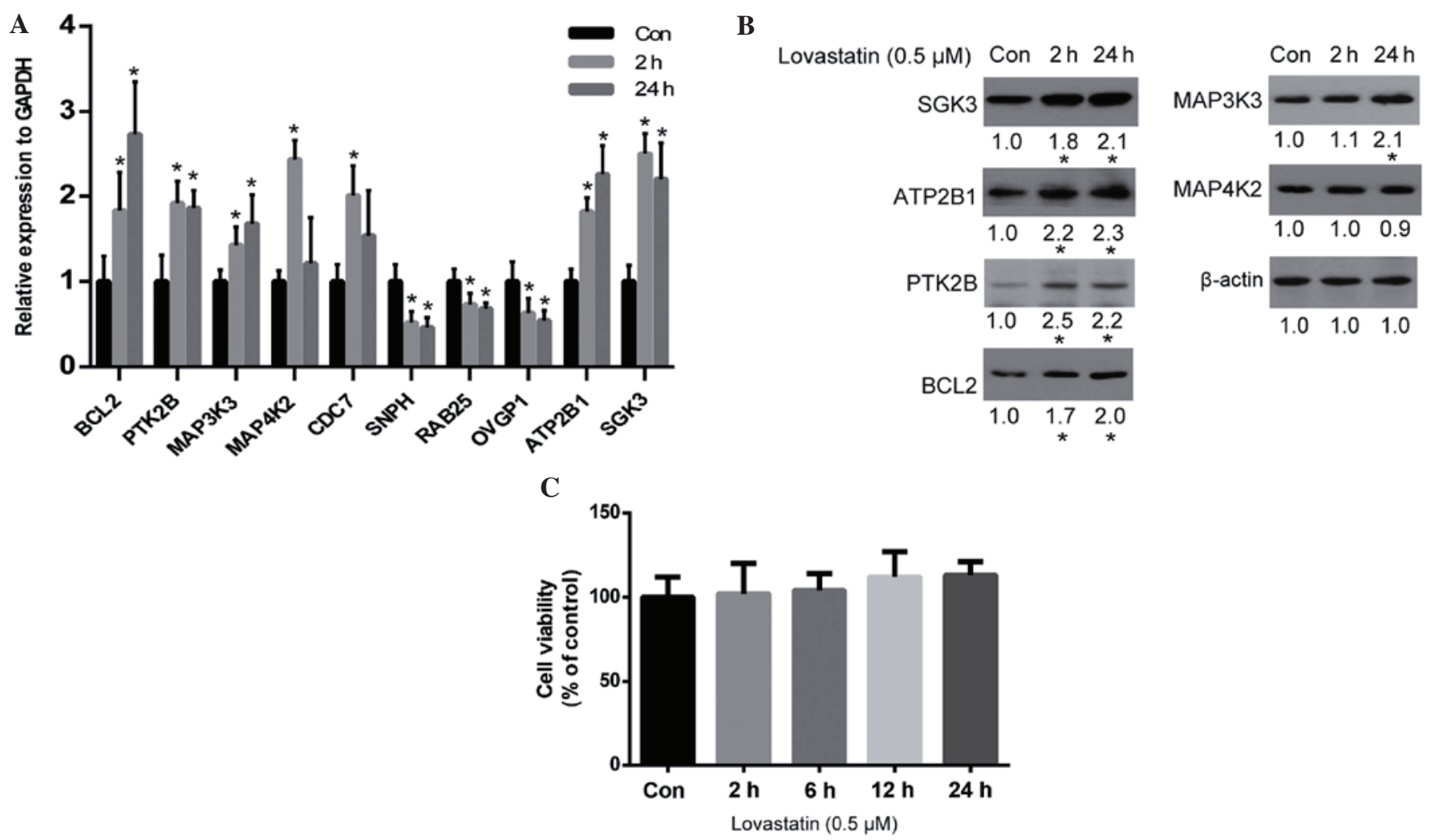

Figure 2. Critical genes regulated by lovastatin. (A) Verification of gene expression by reverse transcription-quantitative polymerase chain reaction. (B) Protein expression levels of genes regulated by lovastatin were analyzed by western blot analysis. (C) The effect of lovastatin on cell viability after $24 \mathrm{~h}$ of treatment, as determined by the cell counting kit- 8 assay. Data are presented as the mean \pm standard deviation of three independent experiments. ${ }^{*} \mathrm{P}<0.05$ vs. the control cells.

Annexin V-positive cells were significantly decreased in the lovastatin plus ox-LDL group, as compared with the ox-LDL group $(\mathrm{P}<0.05$; Fig. $3 \mathrm{C})$, thus further supporting the protective role of lovastatin against ox-LDL-induced HUVEC cytotoxicity.

In the western blot analysis, both PTK2B and BCL2 were upregulated in the lovastatin-treated HUVECs. Since PTK2B serves an important role in cell survival via the AKT pathway (34), and BCL2 is a major anti-apoptotic protein in mitochondrial-dependent apoptosis, it may be hypothesized that this pathway plays an important role in lovastatin-mediated protection against ox-LDL-induced cell injury. As is shown in Fig. 3D, ox-LDL treatment was associated with a downregulation of PTK2B and its downstream p-AKT and eNOS, as well as downregulation of BCL2 and upregulation of the pro-apoptotic protein BAX and cleaved caspase-3. These results suggested that ox-LDL exerted pro-apoptotic effects on mitochondrial-dependent apoptosis. However, treatment with lovastatin was able to reverse these alterations in protein expression, including upregulating PTK2B, p-AKT, eNOS and BCL2, and downregulating BAX and cleaved caspase-3. These alterations in protein expression levels were in parallel with cell viability and apoptosis assays, thus suggesting that these proteins may serve critical roles in lovastatin-mediated protection against ox-LDL-induced cell injury.

Knockdown of PTK2B attenuates ox-LDL-induced HUVEC injury. AKT is known to promote cell survival by upregulating the expression of BCL2 and downregulating the expression of BAX (35). In addition, PTK2B has been shown to be an upstream protein of AKT and eNOS (36). Therefore, it may be hypothesized that PTK2B promotes the AKT/BCL2 signaling cascade. To test this hypothesis, PTK2B expression in HUVECs was transiently knocked down for $48 \mathrm{~h}$ using siRNA, after which HUVECs were treated with ox-LDL for $24 \mathrm{~h}$ to observe the effect of PTK2B on cell viability and apoptosis. The results demonstrated that silencing of $P T K 2 B$ expression significantly decreased cell viability, thus indicating its importance for cell survival in HUVECs (Fig. 4A). Notably, knockdown of PTK2B was able to markedly reduce ox-LDL-induced cytotoxicity. Subsequently, the ox-LDL-induced apoptosis of HUVECs following knockdown of $P T K 2 B$ was analyzed. The ability of ox-LDL to induce apoptosis of HUVECs was markedly compromised following knockdown of PTK2B (Fig. 4B and C). Furthermore, we examined the signaling cascade involved in this pathway. As is shown in Fig. 4D, PTK2B was downregulated following treatment of HUVECs with ox-LDL and siRNA, although the extent of ox-LDL-induced PTK2B downregulation was markedly reduced in $P T K 2 B$ knockdown cells. Accordingly, the ox-LDL-induced inhibition of p-AKT and eNOS, downregulation of BCL2 and upregulation of BAX and cleaved caspase-3 were greatly compromised following knockdown of $P T K 2 B$. These results suggest that the PTK2B-mediated signaling pathway is upregulated by lovastatin and serves an important role in the lovastatin-mediated protection against ox-LDL-induced cytotoxicity. 
A

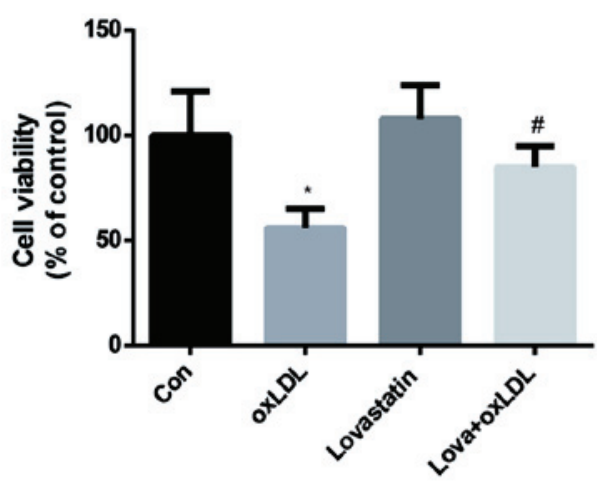

C

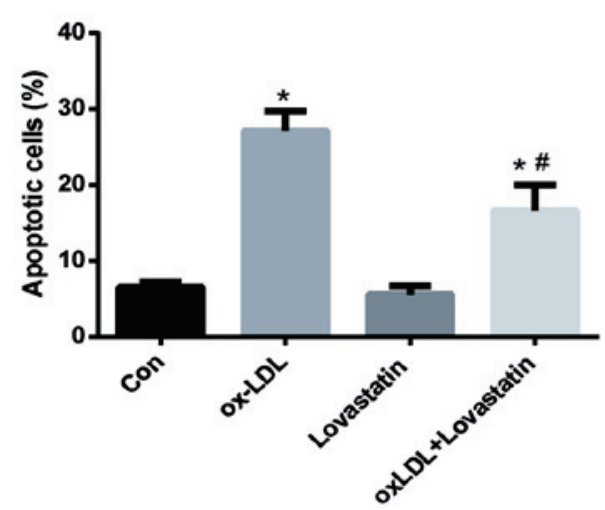

B

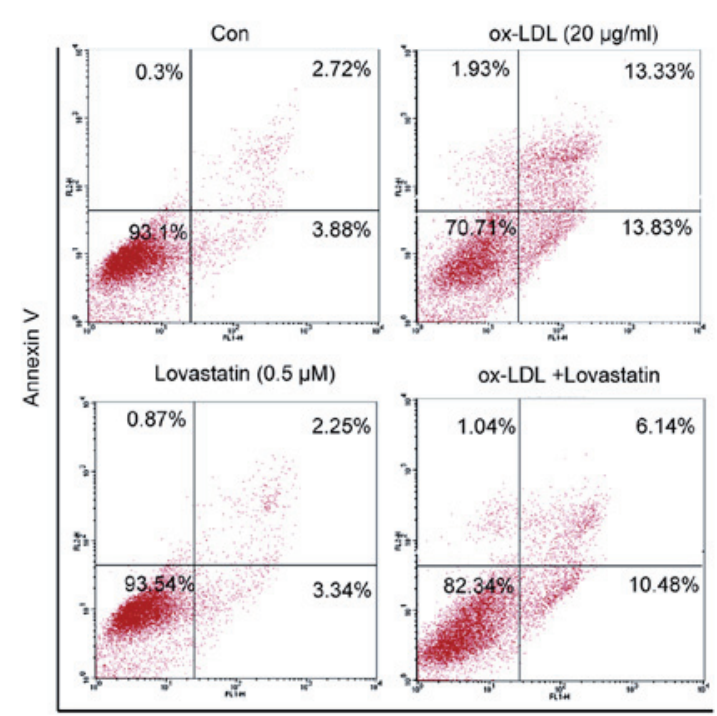

PI

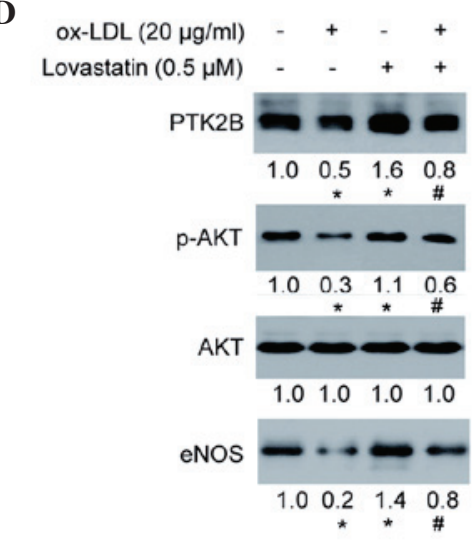

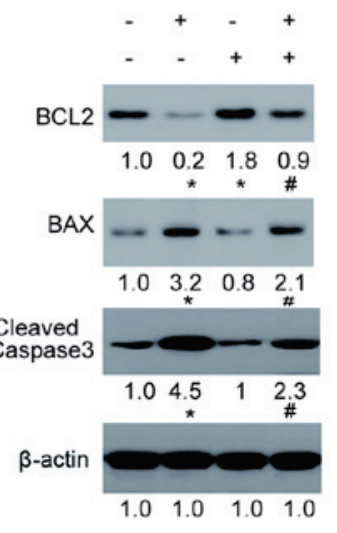

Figure 3. Lovastatin protects HUVECs against ox-LDL-induced cytotoxicity. Cells were treated with $20 \mu \mathrm{g} / \mathrm{ml}$ ox-LDL, $0.5 \mu \mathrm{M}$ lovastatin or a combination of both for 24 h. (A) Cell viability was determined using the cell counting kit-8 assay. (B) Cell apoptosis was assessed by Annexin V and PI staining, followed by flow cytometry. (C) Percentage of apoptotic cells. (D) Protein expression was analyzed by western blotting and band intensities were determined using ImageJ software, following normalization to a control ( $\beta$-actin). Data are presented as the mean \pm standard deviation of three independent experiments. ${ }^{*} \mathrm{P}<0.05$ vs. the control cells; ${ }^{\text {P }}<0.05$ vs. the ox-LDL group. HUVECs, human umbilical vein endothelial cells; ox-LDL, oxidized low-density lipoprotein; PI, propidium iodide.

\section{Discussion}

In the present study, cDNA microarrays were used to identify unknown intracellular targets of lovastatin and potential mediators of the previously observed pleiotropic effects of lovastatin (37). In addition, the gene expression profiles for HUVECs treated with lovastatin at various concentrations and durations were presented.

The present study compared the genes regulated after 2 and 24 h of lovastatin treatment. The results demonstrated that 13 genes were consistently altered following lovastatin treatment for the two different durations, including 4 genes that were downregulated (OVGP1, SNPH, RAB25 and $T M C O 1$ ) and 9 genes that were upregulated, such as ATP2B1, FLJ43663, C7orf29, SGK3, TM4SF4, SLK, BCL2, $C N T N A P 1$ and $P T K 2 B$. Subsequently, the functions of these genes were searched in the Uniprot and PubMed databases in order to obtain useful information for further study; however, only a few of the genes were associated with cell proliferation or survival, including $S G K 3, B C L 2$ and $P T K 2 B$, which were upregulated. $S G K 3$ is serine/threonine-protein kinase that is involved in the regulation of numerous ion channels, cell proliferation, survival and migration $(38,39)$. BCL2 is a well-known anti-apoptotic protein in the mitochondrial-dependent apoptosis signaling pathway. $P T K 2 B$ encodes a cytoplasmic protein tyrosine kinase that is involved in calcium-induced regulation of ion channels and activation of phosphatidylinositol 3-kinase and the AKT signaling cascade $(40,41)$, as well as activation of the MAPK signaling cascade $(42,43)$. Therefore, the authors of the present study hypothesized that lovastatin may promote cell viability via the upregulation of $S G K 3, P T K 2 B$ and $B C L 2$. However, cell apoptosis and viability assays demonstrated that lovastatin did not affect HUVEC viability. These results suggested that lovastatin may exert its beneficial effects via a different mechanism. Therefore, the protective effect of lovastatin against ox-LDL-induced HUVEC cytotoxicity was then investigated. 
A

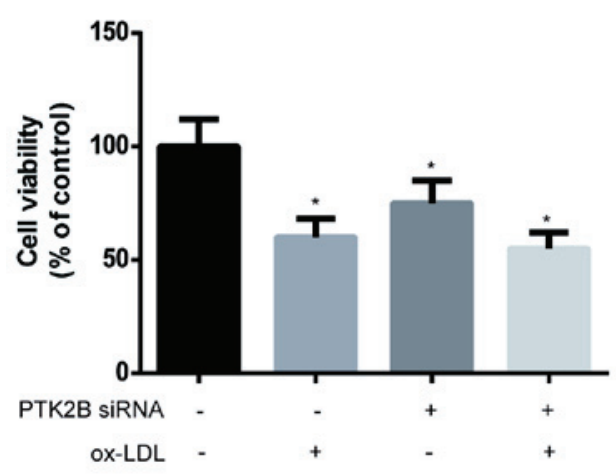

C

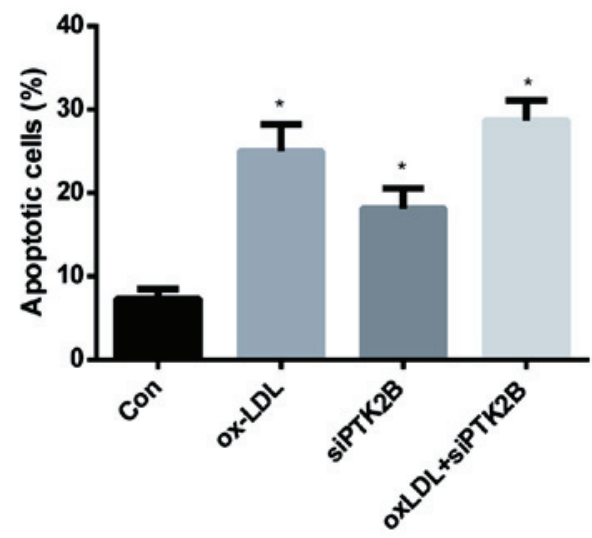

B

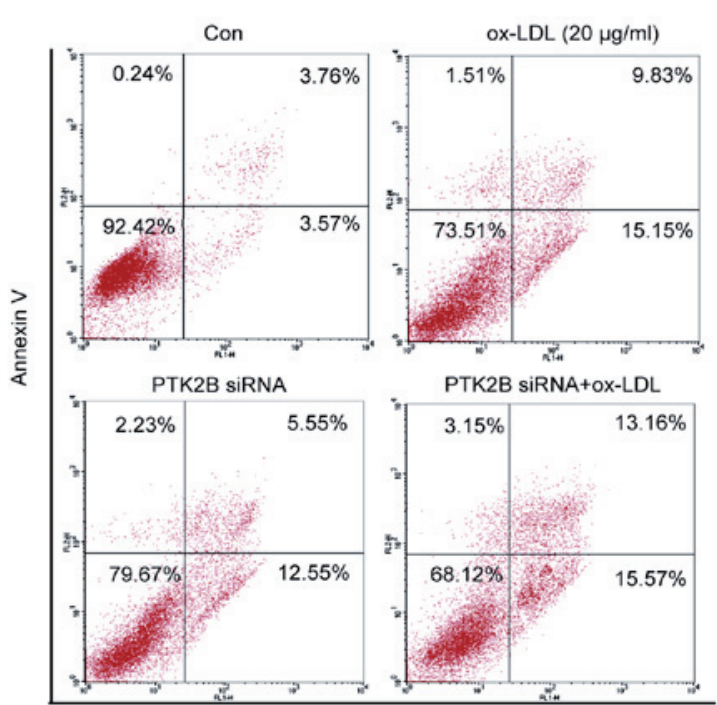

PI

D

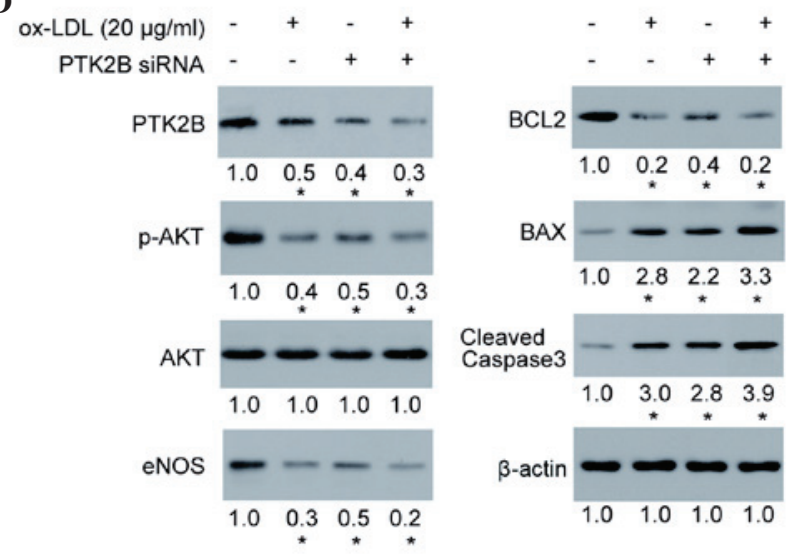

Figure 4. Knock-down of PTK2B expression attenuated ox-LDL-induced HUVEC injury. HUVECs were transiently transfected with $P T K 2 B$ siRNA or scramble siRNA for $48 \mathrm{~h}$, followed by treatment with $20 \mu \mathrm{g} / \mathrm{ml}$ ox-LDL for $24 \mathrm{~h}$. (A) Cell viability was determined using a cell counting kit- 8 assay. (B) Cell apoptosis was determined by Annexin V and PI staining, followed by flow cytometry. (C) Percentage of apoptotic cells. (D) Protein expression was analyzed by western blotting and band intensities were determined using ImageJ software following normalization to a control ( $\beta$-actin). Data are presented as the mean \pm standard deviation of three independent experiments. "P<0.05 vs. the control cells. ox-LDL, oxidized low-density lipoprotein; HUVECs, human umbilical vein endothelial cells; siRNA, small interfering RNA; PI, propidium iodide.

ox-LDL serves a major role during atherogenesis (44), impairs endothelial vasodilator function $(45,46)$ and stimulates apoptosis $(47,48)$. In the present study, lovastatin was able to protect HUVECs against ox-LDL-induced cytotoxicity and cell apoptosis, thus suggesting that some unidentified mechanisms may exist underlying this effect. PTK2B is known to activate the AKT survival pathway to promote BCL2 upregulation, while AKT is an upstream regulator of eNOS, which serves an important role in the protection against ox-LDL $(49,50)$. Based on these previous observations, and since lovastatin upregulated the expression of PTK $2 B$ and $B C L 2$ in the current study, the AKT/BCL-2 signaling pathway was selected for further analysis. The results demonstrated that p-AKT was upregulated in HUVECs following treatment with lovastatin, as well as the upregulation of eNOS and downregulation of BAX. The expression levels of PTK2B, p-AKT and eNOS were downregulated in HUVECs treated with ox-LDL, and this was associated with upregulation of the mitochondrial-dependent apoptosis. Notably, this signaling cascade was inhibited or reversed by lovastatin, thus suggesting that the effects of lovastatin may be mediated via this pathway.

In the present study, $P T K 2 B$ expression was silenced using siRNA in order to observe whether this would alter the effects of lovastatin. Notably, knockdown of PTK2B decreased the downstream expression of p-AKT, eNOS and BCL2, and increased the expression of BAX and cleaved caspase-3, thus confirming that PTK2B plays an important role in this cascade. In addition, knockdown of PTK2B markedly diminished the effect of ox-LDL on this cascade, including the extent to which p-AKT, eNOS and BCL2 were downregulated, and BAX and cleaved caspase-3 were upregulated. These results suggested that PTK2B may exert anti-apoptotic effects against ox-LDL-induced cytotoxicity. Consistent with this, the effects of ox-LDL on HUVEC viability and apoptosis were markedly reduced following knockdown of PTK2B. Therefore, the upregulation of PTK2B served an important role in the ability of lovastatin to protect 
against ox-LDL-induced cell injury. This result is consistent with the findings of previous studies, which demonstrated that PTK2B mediates anti-apoptotic AKT signaling (40), and that upregulation of PTK2B increased cell viability and mobility (51-53).

However, the present study had certain limitations. A number of genes were altered by lovastatin treatment; however, it is difficult to distinguish the 'driver' from the 'passenger' genes, since certain alterations may not be associated with the pharmacological effect of lovastatin. In addition, full integration of the gene profile according to a limited functional study of these genes was challenging, although certain bioinformatics tools were used, including KEGG and DAVID pathway analysis. Furthermore, due to the inherent limitations of microarray and bioinformatics analyses, certain observed alterations may not actually be significant. Therefore, further studies are required to fully analyze the microarray data and to present a comprehensive mechanistic view of the effects of lovastatin on endothelial cells.

In conclusion, the present study investigated the effects of lovastatin on gene expression in HUVECs, and demonstrated that the expression levels of a number of genes were regulated by lovastatin. In addition, certain genes were found to be closely associated with cell survival, in particular $P T K 2 B$ and $B C L 2$, which were upregulated. Thus, it was hypothesized that this effect of lovastatin may be beneficial against endothelial cell injury induced by ox-LDL, a known risk factor for endothelial dysfunction and atherosclerosis. Lovastatin was shown to protect against ox-LDL-induced cytotoxicity, and this protective effect was exerted via the regulation of the signaling cascade involving PTK2B, p-AKT, eNOS, BCL2, $\mathrm{BAX}$ and caspase-3. The present study demonstrated that high-throughput screening technology may be considered a useful tool for mechanistic analyses of drugs.

\section{References}

1. Liao JK and Laufs U: Pleiotropic effects of statins. Annu Rev Pharmacol Toxicol 45: 89-118, 2005

2. Goldstein JL and Brown MS: Regulation of the mevalonate pathway. Nature 343: 425-430, 1990.

3. Ganesh SK, Nass CM and Blumenthal RS: Anti-atherosclerotic effects of statins: Lessons from prevention trials. J Cardiovasc Risk 10: 155-159, 2003.

4. LaRosa JC: Statins and risk of coronary heart disease. JAMA 283: 2935-2936, 2000.

5. Clemenson ND: Statins and risk of coronary heart disease. JAMA 283: 2935, 2000

6. Klag MJ, Ford DE, Mead LA, He J, Whelton PK, Liang KY and Levine DM: Serum cholesterol in young men and subsequent cardiovascular disease. N Engl J Med 328: 313-318, 1993.

7. Goldstein JL and Brown MS: A century of cholesterol and coronaries: From plaques to genes to statins. Cell 26: 161-72, 2015.

8. Massy ZA, Keane WF and Kasiske BL: Inhibition of the mevalonate pathway: Benefits beyond cholesterol reduction? Lancet 347: 102-103, 1996.

9. Wierzbicki AS, Poston R and Ferro A: The lipid and non-lipid effects of statins. Pharmacol Ther 99: 95-112, 2003.

10. Influence of pravastatin and plasma lipids on clinical events in the West of Scotland Coronary Prevention Study (WOSCOPS). Circulation 97: 1440-1445, 1998.

11. Laufs U: Beyond lipid-lowering: Effects of statins on endothelial nitric oxide. Eur J Clin Pharmacol 58: 719-731, 2003.

12. Hilbert T, Poth J, Frede S, Klaschik S, Hoeft A, Baumgarten G and Knuefermann P: Anti-atherogenic effects of statins: Impact on angiopoietin-2 release from endothelial cells. Biochem Pharmacol 86: 1452-1460, 2013.
13. Moncada S, Palmer RM and Higgs EA: Nitric oxide: Physiology, pathophysiology and pharmacology. Pharmacol Rev 43: 109-142, 1991.

14. Rabelink TJ and Luscher TF: Endothelial nitric oxide synthase: Host defense enzyme of the endothelium? Arterioscler Thromb Vasc Biol 26: 267-271, 2006.

15. Sukhova GK, Williams JK and Libby P: Statins reduce inflammation in atheroma of nonhuman primates independent of effects on serum cholesterol. Arterioscler Thromb Vasc Biol 22: 1452-1458, 2002.

16. Giroux LM, Davignon J and Naruszewicz M: Simvastatin inhibits the oxidation of low-density lipoproteins by activated human monocyte-derived macrophages. Biochim Biophys Acta 1165: 335-338, 1993.

17. Arnaud C, Braunersreuther V and Mach F: Toward immunomodulatory and anti-inflammatory properties of statins. Trends Cardiovasc Med 15: 202-206, 2005.

18. Kumai T, Matsumoto N, Koitabashi Y, Takeba Y, Oonuma S, Sekine S, Tadokoro $M$ and Kobayashi S: Pleiotropic effects of 3-hydroxy-3-methylglutaryl-coenzyme A reductase inhibitors: Candidate mechanisms for anti-lipid deposition in blood vessels. Curr Med Chem Cardiovasc Hematol Agents 3: 195-201, 2005.

19. Rasmussen LM, Hansen PR, Nabipour MT, Olesen P, Kristiansen MT and Ledet T: Diverse effects of inhibition of 3-hydroxy-3-methylglutaryl-CoA reductase on the expression of VCAM-1 and E-selectin in endothelial cells. Biochem J 360: 363-370, 2001.

20. Liles WC and Kain KC: Endothelial activation and dysfunction in the pathogenesis of microvascular obstruction in severe malaria-a viable target for therapeutic adjunctive intervention. J Infect Dis 210: 163-164, 2014.

21. Alvarez De Sotomayor M, Herrera MD, Marhuenda E and Andriantsitohaina R: Characterization of endothelial factors involved in the vasodilatory effect of simvastatin in aorta and small mesenteric artery of the rat. Br J Pharmacol 131: 1179-1187, 2000.

22. Bonetti PO, Lerman LO and Lerman A: Endothelial dysfunction: A marker of atherosclerotic risk. Arterioscler Thromb Vasc Biol 23: 168-175, 2003.

23. Matthys KE and Bult $\mathrm{H}$ : Nitric oxide function in atherosclerosis. Mediators Inflamm 6: 3-21, 1997.

24. Ross R: The pathogenesis of atherosclerosis: A perspective for the 1990s. Nature 362: 801-809, 1993.

25. Noll G, Tschudi M, Nava E and Lüscher TF: Endothelium and high blood pressure. Int J Microcirc Clin Exp 17: 273-279, 1997.

26. Kita T, Brown MS and Goldstein JL: Feedback regulation of 3-hydroxy-3-methylglutaryl coenzyme A reductase in livers of mice treated with mevinolin, a competitive inhibitor of the reductase. J Clin Invest 66: 1094-1100, 1980.

27. Huang TH, Peng G, Li GQ, Yamahara J, Roufogalis BD and $\mathrm{Li}$ Y: Salacia oblonga root improves postprandial hyperlipidemia and hepatic steatosis in Zucker diabetic fatty rats: Activation of PPAR-alpha. Toxicol Appl Pharmacol 210: 225-235, 2006.

28. Hitosugi T, Kang S, Vander Heiden MG, Chung TW, Elf S, Lythgoe K, Dong S, Lonial S, Wang X, Chen GZ, et al: Tyrosine phosphorylation inhibits PKM2 to promote the Warburg effect and tumor growth. Sci Signal 2: ra73, 2009.

29. Lang F, Henke G, Embark HM, Waldegger S, Palmada M, Böhmer C and Vallon V: Regulation of channels by the serum and glucocorticoid-inducible kinase - implications for transport, excitability and cell proliferation. Cell Physiol Biochem 13: 41-50, 2003.

30. Husain M, Jiang L, See V, Bein K, Simons M, Alper SL and Rosenberg RD: Am J Physiol 272:C1947-C1959, 1997.

31. Gadepalli R, Singh NK, Kundumani-Sridharan V, Heckle MR and Rao GN: Novel role of proline-rich nonreceptor tyrosine kinase 2 in vascular wall remodeling after balloon injury. Arterioscler Thromb Vasc Biol 32: 2652-2661, 2012.

32. Slattery ML, Lundgreen A and Wolff RK: MAP kinase genes and colon and rectal cancer. Carcinogenesis 33: 2398-2408, 2012.

33. Vogler M: Targeting BCL2-proteins for the treatment of solid tumours. Adv Med 2014: 943648, 2014.

34. Tse KW, Lin KB, Dang-Lawson M, Guzman-Perez A, Aspnes GE, Buckbinder L and Gold MR: Small molecule inhibitors of the Pyk2 and FAK kinases modulate chemoattractant-induced migration, adhesion and Akt activation in follicular and marginal zone B cells. Cell Immunol 275: 47-54, 2012.

35. Maddika S, Ande SR, Panigrahi S, Paranjothy T, Weglarczyk K, Zuse A, Eshraghi M, Manda KD, Wiechec E and Los M: Cell survival, cell death and cell cycle pathways are interconnected: implications for cancer therapy. Drug Resist Updat 10: 13-29, 2007. 
36. Nemoto S, Kobayashi T, Taguchi K, Matsumoto T and Kamata K Losartan improves aortic endothelium-dependent relaxation via proline-rich tyrosine kinase 2/Src/Akt pathway in type 2 diabetic Goto-Kakizaki rats. Am J Physiol Heart Circ Physiol 301: $\mathrm{H} 2383-\mathrm{H} 2394,2011$.

37. Hilbert T, Poth J, Frede S, Klaschik S, Hoeft A, Baumgarten G and Knuefermann P: Anti-atherogenic effects of statins: Impact on angiopoietin-2 release from endothelial cells. Biochem Pharmacol 86: 1452-1460, 2013.

38. Wang Y, Zhou D, Phung S, Masri S, Smith D and Chen S: SGK3 is an estrogen-inducible kinase promoting estrogen-mediated survival of breast cancer cells. Mol Endocrinol 25: 72-82, 2011.

39. Maier G, Palmada M, Rajamanickam J, Shumilina E, Böhmer C and Lang F: Upregulation of HERG channels by the serum and glucocorticoid inducible kinase isoform SGK3. Cell Physiol Biochem 18: 177-186, 2006.

40. Burdick AD, Ivnitski-Steele ID, Lauer FT and Burchiel SW: PYK2 mediates anti-apoptotic AKT signaling in response to benzo[a]pyrene diol epoxide in mammary epithelial cells Carcinogenesis 27: 2331-2340, 2006.

41. Cao J, Chen Y, Fu J, Qian YW, Ren YB, Su B, Luo T, Dai RY, Huang L, Yan JJ, et al: High expression of proline-rich tyrosine kinase 2 is associated with poor survival of hepatocellular carcinoma via regulating phosphatidylinositol 3-kinase/AKT pathway. Ann Surg Oncol 20 (Suppl 3): S312-S323, 2013.

42. Daou GB and Srivastava AK: Reactive oxygen species mediate Endothelin-1-induced activation of ERK1/2, PKB and Pyk2 signaling, as well as protein synthesis, in vascular smooth muscle cells. Free Radic Biol Med 37: 208-215, 2004.

43. Sun CK, Man K, Ng KT, Ho JW,LimZX, Cheng Q,LoCM, Poon RT and Fan ST: Proline-rich tyrosine kinase 2 (Pyk2) promotes proliferation and invasiveness of hepatocellular carcinoma cells through c-Src/ERK activation. Carcinogenesis 29: 2096-2105, 2008.

44. Ross R: Atherosclerosis - an inflammatory disease. N Engl J Med 340: 115-126, 1999.

45. Kugiyama K, Kerns SA, Morrisett JD, Roberts R and Henry PD: Impairment of endothelium-dependent arterial relaxation by lysolecithin in modified low-density lipoproteins. Nature 344: 160-162, 1990.
46. Simon BC, Cunningham LD and Cohen RA: Oxidized low density lipoproteins cause contraction and inhibit endothelium-dependent relaxation in the pig coronary artery. J Clin Invest 86: 75-79, 1990.

47. Dimmeler S, Haendeler J, Galle J and Zeiher AM: Oxidized low-density lipoprotein induces apoptosis of human endothelial cells by activation of CPP32-like proteases. A mechanistic clue to the 'response to injury' hypothesis. Circulation 95: 1760-1763, 1997.

48. Harada-Shiba M, Kinoshita M, Kamido H and Shimokado K: Oxidized low density lipoprotein induces apoptosis in cultured human umbilical vein endothelial cells by common and unique mechanisms. J Biol Chem 273: 9681-9687, 1998.

49. Chavakis E, Dernbach E, Hermann C, Mondorf UF, Zeiher AM and Dimmeler S: Oxidized LDL inhibits vascular endothelial growth factor-induced endothelial cell migration by an inhibitory effect on the Akt/endothelial nitric oxide synthase pathway. Circulation 103: 2102-2107, 2001.

50. Kotamraju S, Hogg N, Joseph J, Keefer LK and Kalyanaraman B Inhibition of oxidized low-density lipoprotein-induced apoptosis in endothelial cells by nitric oxide: Peroxyl radical scavenging as an antiapoptotic mechanism. J Biol Chem 276: 17316-17323, 2001.

51. Sun CK, Ng KT, Lim ZX, Cheng Q, Lo CM, Poon RT, Man K, Wong N and Fan ST: Proline-rich tyrosine kinase 2 (Pyk2) promotes cell motility of hepatocellular carcinoma through induction of epithelial to mesenchymal transition. PLoS One 6: e18878, 2011.

52. Lim ST, Miller NL, Nam JO, Chen XL,Lim Y and Schlaepfer DD Pyk2 inhibition of p53 as an adaptive and intrinsic mechanism facilitating cell proliferation and survival. J Biol Chem 285: 1743-1753, 2010.

53. Yoon H, Choi YL, Song JY, Do I, Kang SY, Ko YH, Song S and Kim BG: Targeted inhibition of FAK, PYK2 and BCL-XL synergistically enhances apoptosis in ovarian clear cell carcinoma cell lines. PLoS One 9: e88587, 2014. 